\title{
GREGORIO BARTOLOMÉ REMACHA (FL. 1715-1754): RUTAS METODOLÓGICAS PARA EL REDESCUBRIMIENTO DE UN MAESTRO DE CAPILLA
}

\author{
GREGORIO BARTOLOMÉ REMACHA (FL. 1715-1754): \\ METHODOLOGICAL PATHS IN ORDER TO REDISCOVER A \\ CHAPEL-MASTER
}

Edgar Alejandro Calderón Alcántar

Universidad Nacional Autónoma de México

\section{Resumen:}

El presente artículo tiene la primordial intención de aproximarse a la trayectoria artística del maestro de capilla español Gregorio Bartolomé Remacha, de quien se conservan composiciones en ambos lados del Océano Atlántico, pero que, sin embargo, es un autor desconocido en el ámbito de la musicología hispanoamericana. Tomando como punto de partida las obras de éste conservadas en el Archivo Musical del Colegio de Santa Rosa, que hoy en día custodia el Conservatorio de las Rosas (Morelia, Estado de Michoacán, México), se mostrarán las estrategias metodológicas para el redescubrimiento de este músico, en el propio orden que reflejó la investigación.

\section{Palabras Clave:}

Gregorio Remacha, Siglo XVIII, Colegio de Santa Rosa, Morelia, Michoacán, México, Real Iglesia de San Cayetano de Madrid, Iglesia Magistral de Alcalá de Henares (Madrid), Colegiata de Toro (Zamora), Impresos de letras de villancicos.

\begin{abstract}
:
The main purpose of the present article is to establish a first approach to the artistic career of Spanish chapel master Gregorio Bartolomé Remacha, whose compositions survive on both sides of the Atlantic, but is otherwise unknown in the context of Hispanoamerican Musicology. Taking as the starting point for this undertaking his pieces formerly housed at the Archivo Musical del Colegio de Santa Rosa, nowadays in the custody of the Conservatorio de las Rosas (Morelia, state of Michoacán, México), it will show the methodological strategies leading towards a rediscovery of this musician, in the same order as that followed in the present research.
\end{abstract}

Key words:

Gregorio Remacha, Eighteenth Century, Colegio de Santa Rosa, Morelia, Michoacán, México, Real Iglesia de San Cayetano (Madrid), Iglesia Magistral de Alcalá de Henares (Madrid), Colegiata de Toro (Zamora), Printed Lyrics of Villancicos. 


\section{INTRODUCCIÓN}

Cuando Miguel Bernal Jiménez (*1910; †1956) publicó la monografía El Archivo Musical del Colegio de Santa Rosa de Santa María de Valladolid, en el año de 1939¹, la musicología mexicana enfocada en el periodo virreinal, en particular en el siglo XVIII, vivió uno de sus primeros y más importantes impulsos. En su encomiable trabajo, Bernal incluyó un catálogo de las obras que en aquel momento contenía el citado fondo documental.

Dentro del corpus de manuscritos conservados en este fondo, figuraban músicos con mayor número de títulos, entre ellos: Gregorio Remacha, Francisco Moratilla, José Gabino Leal, Francisco Javier Ortiz de Alcalá, José de Nebra, etc.; sin embargo, Bernal no logró identificar a gran cantidad de los compositores; y en dicha circunstancia estaba el maestro de capilla Gregorio Remacha.

A más de setenta años de distancia de aquella publicación del compositor y musicólogo michoacano, el contenido del archivo musical del colegio vallisoletano ${ }^{2}$ ha sufrido cambios devastadores, entre ellos la pérdida de varias obras que interesaron en primera instancia al maestro Miguel Bernal Jiménez $z^{3}$; sin embargo, un aspecto se ha mantenido constante: Gregorio Remacha, con sus ocho villancicos ${ }^{4}$, es, junto a José Gabino Leal, el compositor con más obras en dicho archivo.

En tales circunstancias era preciso responder las siguientes interrogantes: ¿Quién fue realmente Gregorio Remacha?, ¿qué origen tuvo?, ¿estuvo activo en Valladolid de Michoacán?

1 BERNAL JIMÉNEZ, 1939.

2 De acuerdo con R. Murillo, y con base en un acta de 18.05.1541, la actual ciudad de Morelia, capital del Estado de Michoacán, en México, se fundó con el nombre de Ciudad de Mechoacán, en el Valle de Guayangareo, por orden del virrey "de la Nueva España" Antonio de Mendoza. Más tarde, en 1545 se le denominó Valladolid (de Michoacán) y así se mantuvo hasta 1828, en que tomó el nombre de Morelia en honor al sacerdote y militar José María Morelos y Pavón (*1765; †1815), uno de los principales pilares del movimiento de independencia mexicano, que nació en esta ciudad. Cfr:: MURILLO DELGADO, 1990. En relación al Archivo Musical del Colegio de Santa Rosa, conviene señalar que dicho colegio "de niñas de Santa Rosa de Santa María”, se fundó en 1743 por orden y auspicio del obispo Francisco Pablo Matos Coronado, quien, tras ocupar la sede del Yucatán (1734-1741), fue obispo de Valladolid de Michoacán (1741-†1744). Hoy en día, las instalaciones del colegio vallisoletano corresponden al Conservatorio de las Rosas, y el archivo musical del siglo XVIII lo custodia el mismo conservatorio.

3 El compositor, organista, director de coros, pedagogo y musicólogo Miguel Bernal Jiménez, realizó un concierto con material del Archivo de Música del Colegio de Santa Rosa, que se llevó a cabo en el Teatro Ocampo, de la ciudad de Morelia, el martes 30.05.1939 a las 21:00 horas. En dicho recital se interpretaron dos oberturas orquestales, una del ministril y timbalero Antonio Sarrier $(† 1761)$ y otra del flautista Antonio Rodil $(* 1710$ c; $† 1787)$; dos sonatas para guitarra de autor anónimo; así como dos villancicos de Francisco Moratilla (acaso el mismo músico que constaba como maestro de capilla de la Iglesia Magistral de Alcalá de Henares en 1735, y que fuera profesor de música y gramática del luego famoso Antonio Rodríguez de Hita); los manuscritos correspondientes a las composiciones señaladas han dejado de formar parte del archivo en cuestión, al menos, desde la década de 1980, en cuyo inventario firmado por el entonces rector del Conservatorio de las Rosas, Jesús Carreño, ya no aparecen dichas obras. Por otro lado, también se advierte que varios manuscritos que figuraban en la categoría de incompletos en el catálogo de Bernal, fueron reinventariados como obras completas después de cotejar con otros manuscritos y encontrar correspondencias precisas entre ellos. Estas tareas fueron producto del trabajo de reorganización, inventariado y restauración del archivo por parte de la Cátedra de Musicología del Conservatorio de las Rosas, bajo la dirección de Mercedes de León y Pierluigi Ferrari.

4 Este fondo musical que está nutrido esencialmente por villancicos y cantadas, contiene actualmente ocho títulos de Gregorio Remacha, de los cuales solamente tres se encuentran completos: Venid al combite, A esta espiga tierna y Luz gloriosa, los cuales están dispuestos para cuatro voces, dos violines y acompañamiento; Al sol entre sombras, Ay dulce amor y Sobre el pan de los cielos categóricamente se encuentran entre las obras incompletas, pero por faltarles sólo una o dos partes, permiten plantearse una idea general del diseño y elementos constitutivos de las mismas, como por ejemplo: la estructura global, la armonía, recursos contrapuntísticos, etc. Por el contrario, Bibientes pasajeros y Bagel pues que felice, presentan escaso material, y por tal razón estuvieron incluidos en una sección del archivo llamada "pedacería". 
La primera entrada que he localizado de un diccionario musical del siglo XX, centrada específicamente en Gregorio Bartolomé Remacha, la publicaron en 1954 J. Pena e H. Anglés ${ }^{5}$.

Debido a lo sustancial que representa este trabajo, la reproduzco íntegramente:

"Remacha, Gregorio Bartolomé. Compositor español de principios del siglo XVIII; en 1718 fue maestro de capilla de la iglesia de S. Cayetano, de Madrid; contemporáneo del célebre José de Nebra. Obras: Montserrat, Arch. Musical, Parce a solo de cont., con V. y Fl; el villancico a 4 v. En confusa horrible guerra ${ }^{6}$; Lauda Sion, secuencia a 8 v. (1718)".

La información que ofrece la cita anterior es bastante discreta, no proporciona prácticamente datos biográficos, pero sí asienta el año que estuvo activo en la iglesia madrileña de San Cayetano, es decir, 1718, al tiempo que dirige a tres composiciones de éste conservadas en el archivo de música de la Abadía de Montserrat.

Por otra parte, varias décadas después, C. Alonso, escribió una nueva entrada correspondiente a Gregorio Remacha?:

"Remacha, Gregorio Bartolomé. España, siglo XVIII. Maestro de capilla. Autor citado por Soriano Fuertes y Saldoni como MC de la real iglesia de San Cayetano de Madrid, en la que existió una capilla de música hasta la invasión francesa en 1808. En el archivo de El Escorial (Madrid) se encuentran tres obras de Remacha de estética barroca: Ave Maris. 8V, órg; A Belén corte del niño. 8V, Vill, órg y Oíd Montes. 8V, órg.".

Como puede observarse, el panorama no mejoró mucho; ni siquiera existe unificación con la entrada anterior, es decir, con el año 1718, en que según Pena y Anglés, Remacha ejercía el magisterio de capilla en San Cayetano; pero la cita de C. Alonso remite a otras tres obras conservadas en archivo de El Escorial.

Tras el árido entorno referencial que se poseía de este autor, la investigación tuvo que centrarse momentáneamente en los datos exhibidos en los propios papeles de música del citado archivo musical en Morelia. En las portadillas de las obras se pueden observar datos interesantes:

5 PENA y ANGLÉS, tomo II, 1954: 1856.

6 Una vez que me fue posible la consulta de los manuscritos musicales vía digital, es menester señalar que el villancico a 4, “de Pasión", En confusa horrible guerra, incluye la fecha de copia del año de 1730.

7 ALONSO, Tomo 9, 2002: 97. 


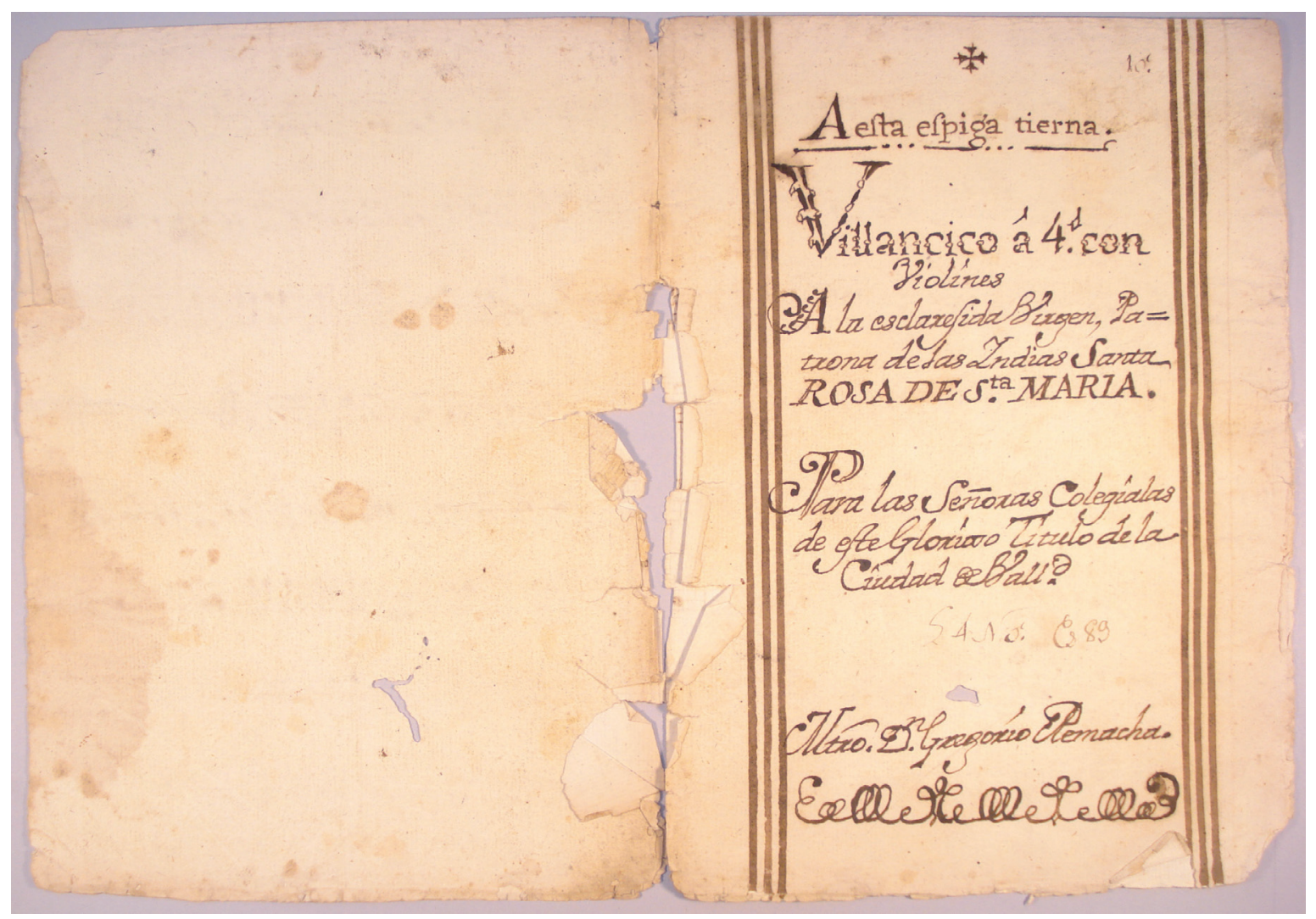

Figura 1. Portada del villancico A esta espiga tierna, de Gregorio Remacha Archivo de Música del Colegio de Santa Rosa, Morelia (México), sig. 061

La portadilla de este villancico incluye una primera dedicatoria a la patrona del Colegio, Santa Rosa de Lima, así como una segunda dirigida a las colegialas de la institución vallisoletana y, manteniendo uniformidad en la caligrafía, se lee el nombre del autor: Gregorio Remacha. Dichos aspectos podrían suponer, en primera instancia, que el propio Remacha (o alguien — un copiante- en su nombre) hubiera extendido tan elocuentes inscripciones, con la posibilidad de haber estado al servicio del Colegio o cerca de éste, es decir, en el ámbito catedralicio. Este sutil argumento lo sugieren también las fechas inscritas en otras portadillas de villancicos de este autor como son Sobre el pan de los cielos, villancico a 7, cuya fecha de copia corresponde a 1738; Al sol entre sombras, villancico a 8, copiado en 1741; o el villancico a 4 con violines, Venid al combite ${ }^{8}$, del año de 1760. Con lo anterior puede vislumbrase una inicial hipótesis en

8 Mantengo la ortografía original de los manuscritos, de manera que no se hace el cambio "combite" por "convite". Este villancico se conserva en el Archivo de Música del Colegio de Santa Rosa, Morelia (México), sig. 060. 
la que una vez que Remacha culminara su magisterio en Madrid en 1718, pudo haber viajado a la Nueva España y establecerse en Valladolid de Michoacán en las fechas señaladas. Sin embargo, dicha hipótesis no observa fundamentos completamente sólidos.

Entre 1995 y 2007, G. Pareyón publicó dos diccionarios relacionados con la música en México; en ambos, existen entradas respectivas a Gregorio Remacha. La primera de ellas cita lo siguiente:

"Remacha, Gregorio (s. XVIII). Compositor y organista activo en Valladolid (hoy Morelia). Autor de música religiosa; algunas obras suyas, con diversas fechas entre 1738 y 1760, son conservadas en el archivo musical del Colegio de Santa Rosa de Santa María"9.

Como se puede verificar, Pareyón ratifica la sospecha inicial, sin embargo, no proporciona referencia alguna para confirmarla documentalmente. Por otra parte, el mismo autor vuelve sobre Remacha en el Diccionario Enciclopédico de Música en México ${ }^{10}$, en el cual básicamente reproduce la entrada de su publicación anterior:

"Remacha, Gregorio ( $f$. Valladolid, hoy Morelia, s. XVIII). Organista y compositor. Autor de música religiosa; algunas composiciones suyas, fechadas entre 1738 y 1760, se conservan en el archivo musical del Colegio de Santa Rosa de Santa María. Fuente: 1939. Miguel Bernal Jiménez: El archivo musical del Colegio de Santa Rosa de Santa María de Valladolid [...] 45 páginas".

Al señalar la fuente de consulta, G. Pareyón delimita el panorama, pero al mismo tiempo deja ver que realizó una interpretación incorrecta, ya que en la citada monografía de Miguel Bernal no se encuentra ese informe; por el contrario, como se dijo antes, Bernal no logró identificar a Remacha.

Un título que sugería interesantes perspectivas y esperanza para los fines de esta investigación, por el contexto que enmarca, fue el cuarto volumen de la Historia de la música española ${ }^{11}$, a cargo de Antonio Martín Moreno; este tomo se circunscribe al siglo XVIII; sin embargo, el nombre del maestro de capilla en cuestión se menciona sólo una vez. Dicha cita aparece de manera ocasional, mientras se narra que a partir de la muerte de Simón Araya en 1738, la catedral de León se encontraba sin maestro de capilla titular, y sin embargo,

"el cabildo no se preocupó por cubrir de inmediato la plaza, sino que invitaba a los maestros cercanos en las principales fiestas, como al maestro de capilla de la Colegial de Coro [sic. Toro] Gregorio Remacha""2.

9 PAREYÓN, 1995: 472.

10 PAREYÓN, tomo II, 2007: 876.

11 MARTÍN MORENO, vol. 4, 1985: 122.

12 Ibídem. Hay una errata en la ortografía de la sede, debe decir Colegiata de Toro. No se da referencia o nota a pie de página para conocer el origen de esta información que ayudaría sin duda a iluminar los profundos huecos, que como se ha podido comprobar, presenta todavía la historia de este compositor. 
Dentro de una monografía sobre Santa Rosa de Lima ${ }^{13}$, en el apartado de conclusiones, se citan algunas obras musicales escritas en honor a la mencionada santa, entre las cuales se encuentra un villancico de Gregorio Remacha; por esta razón, creo menester transcribir literalmente las siguientes líneas:

“[...] En lo que a músicos se refiere, cabe recordar algunas obras del siglo XVII compuestas en su honor en México y escasamente conocidas: Salve Lima que adoras; el villancico a cuatro voces con violines del maestro Gregorio Remacha: A la esclarecida Virgen, Patrona de las Indias, Santa Rosa de Santa María y dedicado por su autor a las alumnas del Colegio de Santa María de Valladolid (hoy Morelia); otro villancico a cuatro voces, por el maestro también mexicano José Gavino Leal, en 1767; y el igualmente villancico, a cuatro voces solamente, A Santa Rosa de Santa María [...]"14.

A primera vista, la citada reseña habría que tomarla con cautela, ya que, aunque en el corpus de obras que conforman el archivo musical citado existen algunas de los siglos XVI y XVII, hay que señalar que el Colegio de Santa Rosa no se fundó hasta $1743^{15}$, y para que las obras en cuestión fuesen dedicadas por el autor a las colegialas de dicha institución resultaría imprescindible que la misma estuviera ya en funcionamiento; aunque bien podría tratarse sólo de error de escritura y en realidad haya querido referirse al siglo XVIII. Otro rasgo que salta a la vista es que el párrafo citado hace entender que los compositores José Gabino Leal y Gregorio Remacha son mexicanos, pero no se ofrece una cita para justificar dichas aseveraciones.

Tras una exhaustiva revisión de las actas capitulares correspondientes al Colegio de Santa Rosa y a la Catedral de Morelia, respectivamente, no se ha encontrado rastro alguno de Gregorio Remacha. Como ya se dijo antes, el entorno biográfico sobre el compositor, con base en fuentes españolas del siglo XX, tampoco era lo suficientemente nítido. En virtud de lo anterior, la investigación tendría que desarrollarse en la península ibérica, con otro tipo de fuentes documentales: manuscritos musicales, actas capitulares y documentos impresos del siglo XVIII' ${ }^{16}$.

Es conveniente señalar que las fuentes bibliográficas correspondientes al siglo XIX y el primer tercio del siglo XX presentan un perfil informativo mucho más sólido en torno a Gregorio Remacha que las que ya han sido referidas, de fechas posteriores. Entre los autores que mencionan, aunque tangencialmente, a este compositor, se encuentran algunos célebres musicólogos y musicógrafos españoles: Mariano Soriano Fuertes, en su Historia de la música española..${ }^{17}$ menciona a Remacha como un distinguido maestro de capilla de la Real de San Cayetano. Soriano presenta a este maestro

13 FLORES ARAOZ, 1995: 298

14 Ibídem.

15 Acta referente a la Muerte de Francisco Pablo Matos Coronado fundador del Colegio de Santa Rosa, Archivo Histórico “Manuel Castañeda Ramírez" GobiERnos / COLEGIOS / SANTA Rosa 1729-1750 / Expediente número 1 N5. Véanse también: BERNAL JIMÉNEZ, 1939. CARREÑO: 1979.

16 Agradezco significativamente la guía y consejo de Antonio Ezquerro Esteban, Javier Marín López, Ismael Fernández de la Cuesta, María Gembero Ustárroz y Rosa Isusi Fagoaga, pero muy especialmente quiero resaltar la generosidad y sabiduría del padre José López-Calo.

17 SORIANO-FUERTES Y PIQUERAS, tomo IV, 1859: 99, 116. 
en el contexto de las capillas reales a principios del siglo XVIII, en que figuraban músicos como el conocido compositor y organista José de Nebra, afirmando que las obras que se conservan de estos compositores son dignas del mayor respeto; por su parte, Baltasar Saldoni ${ }^{18}$, sitúa a Remacha como maestro de capilla de San Cayetano de Madrid en 1718. Además de señalar que en dicha iglesia existía una capilla de música como en los monasterios de La Encarnación y de las Descalzas, manifiesta que estas corporaciones de artistas realizaban funciones en otras iglesias de Madrid, y que tales capillas se mantuvieron unidas hasta la invasión de los franceses en el año de 1808. Saldoni reconoce también no haber visto obra alguna de Remacha para poder estudiar su estilo, pero lo que resulta más trascendente es que este autor menciona con toda precisión la referencia de Remacha publicada anteriormente por Soriano Fuertes; y finalmente, Felipe Pedrell ${ }^{19}$ publicó apenas entrando el siglo XX un vehemente trabajo, tanto por su contenido como por la repercusión que representó para su época: el catálogo de la biblioteca musical de la Diputación de Barcelona, en que se cita, además de una carta al organista, compositor, tratadista y compilador de música franciscano fray Antonio Martín y Coll (*1680c; †1734p) —activo en Alcalá de Henares y Madrid—, la existencia de un Laudate Dominum omnes gentes, a 7, bajo la autoría de Remacha. En palabras de Pedrell "Fou mestre de Sant Gayetà de Madrid a principis de segle XVII"20. En torno a la referencia del siglo XVII debe tratarse de una nueva errata, esta vez en la redacción de Pedrell, y deba decir a principios del siglo XVIII.

Rafael Mitjana reafirma, en los primeros años del siglo XX, que Gregorio Bartolomé Remacha era maestro de capilla de la iglesia de San Cayetano ${ }^{21}$, dentro del ámbito de las diferentes capillas reales, mencionando también a los maestros de capilla contemporáneos a Remacha, como es el caso del renombrado José de Torres y Martínez Bravo en la Capilla Real, Diego de las Muelas en La Encarnación, y José de San Juan en las Descalzas Reales.

\section{ASPECTOS BIOGRÁFICOS}

Con base en las circunstancias señaladas previamente, es preciso aproximarse a la trayectoria artística y aspectos biográficos de este compositor a través de diferentes tipos de fuentes documentales: actas capitulares, las propias obras musicales manuscritas, etc.; sin embargo, en el presente estudio los pliegos impresos de letras de villancicos han desempeñado un papel capital tanto para asentar las fechas de sus magisterios de capilla, como también son de vital importancia para el estudio del villancico, tanto en cuestiones literarias como de estructura e interpretación musical.

18 SALDONI, tomo IV, 1868-1881: 273.

19 PEDRELL, vol. I, 1908: 234, 261.

20 Ibídem, p. 261; traduciendo al castellano: “[...] fue maestro de capilla de San Cayetano de Madrid a principios del siglo XVII [...]”. Debe insistirse en que se trata de una errata, ya que en la página 234 del mismo catálogo se le señala como maestro de capilla en San Cayetano en 1718.

21 MITJANA, vol. IV, 1920: 2144. 
El primer dato sobre Gregorio Remacha que he logrado localizar hasta ahora es que fue maestro de capilla de la Real Iglesia de San Cayetano ${ }^{22}$, de Madrid, el año de $1715^{23}$.

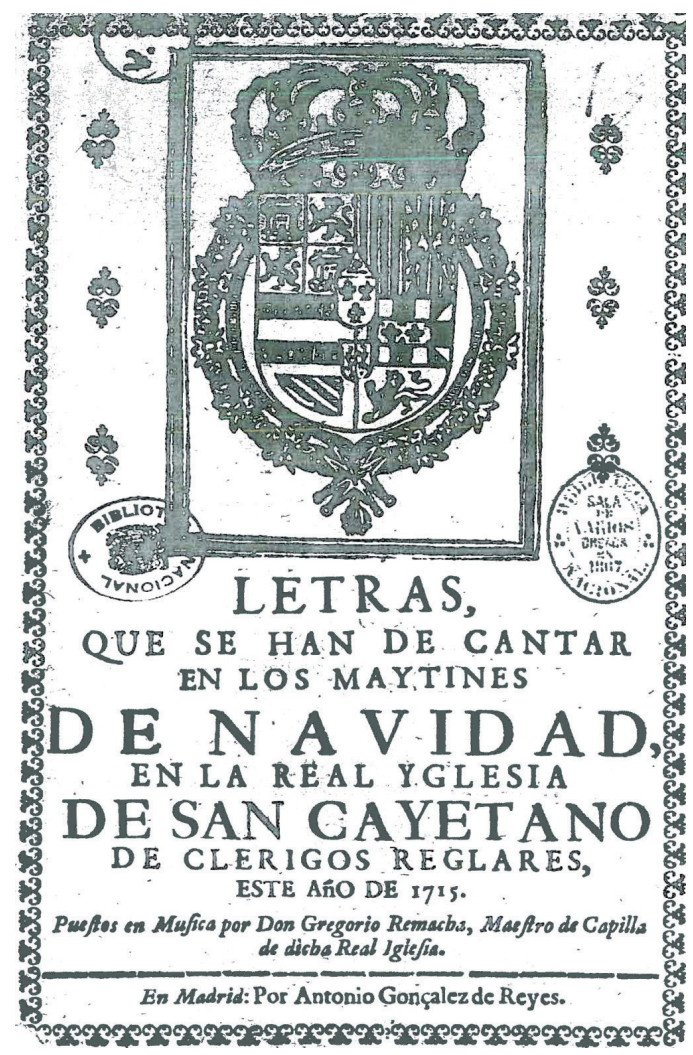

Figura 2. Portadilla del impreso con letras de villancicos de 1715, $\boldsymbol{E}-\mathbf{M n}$, sig. VE/906/23

22 De acuerdo a GUTIÉRREZ ÁLVAREZ, 2005: 44-45, existen fuentes que datan del siglo XVIII que atribuyen la fundación del Convento de San Cayetano de Madrid al monje Plácido Mirto en 1644. Más tarde se la conoció también como antigua iglesia del convento de Nuestra Señora del Favor, aunque por ser de clérigos teatinos fue más conocida por el nombre del fundador de la orden: San Cayetano de Tiena. Posteriormente, debido al aumento del número de frailes, se decidió construir un nuevo templo en el mismo lugar en que se encontraba el oratorio primitivo. La construcción de este nuevo edificio fue muy lenta: el proyecto inicial se le encargó, alrededor de 1672, al arquitecto Marcos López y no se inauguró oficialmente hasta el 06.08.1761, día de San Cayetano, por cierto con una solemne ceremonia a la que acudió el propio rey Carlos III. Durante estos casi noventa años de construcción, también participaron escultores y arquitectos de la talla de José de Churriguera y Pedro de Ribera, éste a partir de 1722, trabajos que contribuyeron a que San Cayetano llegara a ser uno de los templos de mayor importancia artística de Madrid en el siglo XVIII. En dichas circunstancias, difícilmente Remacha pudo conocer este templo completado, por lo menos mientras ejerció como maestro de capilla de este lugar. Después de los lamentables hechos del 19.07.1936, tras las explosiones provocadas por la recién estallada Guerra Civil española, la iglesia tuvo que volver a reconstruirse a partir de los diseños originales, y hoy en día parece no haber ningún rastro de aquel desastre; sin embargo, los tesoros documentales son irrecuperables.

23 Para la celebración del oficio de maitines de la Navidad del año de 1715 se imprimieron las "Letras de los villancicos que se han de cantar en la Real iglesia de San Cayetano de Clérigos Reglares, puestos en música por Don Gregorio Remacha, maestro de capilla de dicha Real Iglesia”. Dicha impresión corrió a cargo de Antonio González de Reyes. Un ejemplar de este impreso se localiza en la Sala Cervantes de la Biblioteca Nacional de España: $\boldsymbol{E}-\boldsymbol{M n}$, VE/906/23. El catálogo de $\boldsymbol{E}-\boldsymbol{M n}$, puede ser consultado vía Internet a través del siguiente enlace: www.catalogo.bne.es 
Sin embargo, existen argumentos para especular que Remacha haya ejercido el cargo de manera interina desde 1711, o bien para sólo sugerir que en el oficio de maitines de Navidad de ese año compuso por lo menos el villancico A Belén corte del niño. El manuscrito de este villancico ${ }^{24}$ se encuentra en la Real Biblioteca del Monasterio de San Lorenzo de El Escorial, $\boldsymbol{E}$-E, sig. 88-20.

Cotejando los papeles de música y el impreso de las "Letras de los villancicos que se han de cantar [...] en la Iglesia de San Cayetano [...] en los maitines de Navidad de 1711”, E-Mn, sig. VE/906/22, éstos coinciden perfectamente en texto y estructura, lo que sugiere que haya sido compuesto ese mismo año por Remacha; pero lo cierto es que el impreso no menciona el nombre del maestro de capilla de turno. Por lo tanto, a día de hoy, no hay manera de corroborar documentalmente que Remacha ya era maestro de capilla de la iglesia de San Cayetano desde 1711, ya que la mayor parte de los archivos de esta iglesia se quemaron a causa de actos vandálicos ocurridos durante la Guerra Civil española el 19.07.1936 25 .

No obstante, en referencia a este lamentable acontecimiento en el citado templo de San Cayetano (al fracturado entorno que deja el no tener fuentes de consulta), con los datos que se tienen a la mano, se pueden trazar ciertos bosquejos que ayuden a llenar los significativos huecos que han impedido que la historia de los músicos de esta iglesia pueda dilucidarse.

El compositor Antonio de Yanguas (*Medinaceli, 1682; †Salamanca, 1753) ${ }^{26}$ fue nombrado maestro de capilla de esta iglesia de San Cayetano a principios de 1708. A finales de ese año es elegido maestro de música en el Colegio del Rey, también en Madrid, sin dejar su puesto en San Cayetano; hasta que el 10.04.1710 obtuvo el nombramiento de maestro de capilla de la catedral metropolitana de Santiago de Compostela.

Por lo anterior se podría entrever que el siguiente maestro de capilla de San Cayetano hubiera sido Gregorio Remacha, incluso desde 1710 a la partida de Yanguas, pero lo que resulta palpable es que lo fue a partir de 1715 .

El 02.09.1718 Gregorio Bartholomé27 Remacha escribió una elegante carta respuesta a fray Antonio Martín y Coll, autor del tratado de teoría musical Arte de Canto Llano; carta que se incluyó y publicó, al año siguiente, en las hojas introductorias al dicho tratado. El contenido de esta epístola ayuda a comprender la cercana relación de Remacha con Martín y Coll y su manifiesto interés en la teoría musical.

\footnotetext{
24 Este villancico ha sido transcrito y estudiado por el autor del presente artículo: CALDERÓN ALCÁNTAR, 2010.

25 Según el actual párroco de la Iglesia de San Cayetano, hoy sólo se conservan algunas partidas de bautismo, matrimonio y defunción, aseverando que las actas capitulares y el archivo musical no existen ya. Entrevista de 28.07.2009, en la mencionada iglesia, ubicada en la calle Embajadores, de Madrid.

26 TORRENTE, Álvaro, vol. 27, 2001: pp.639-640.

27 Con esta ortografía Remacha publicó su segundo nombre, el cual no siempre se incluye en las portadas de las obras musicales; la mayor parte dicen Gregorio Remacha; algunas, solamente Remacha.
} 


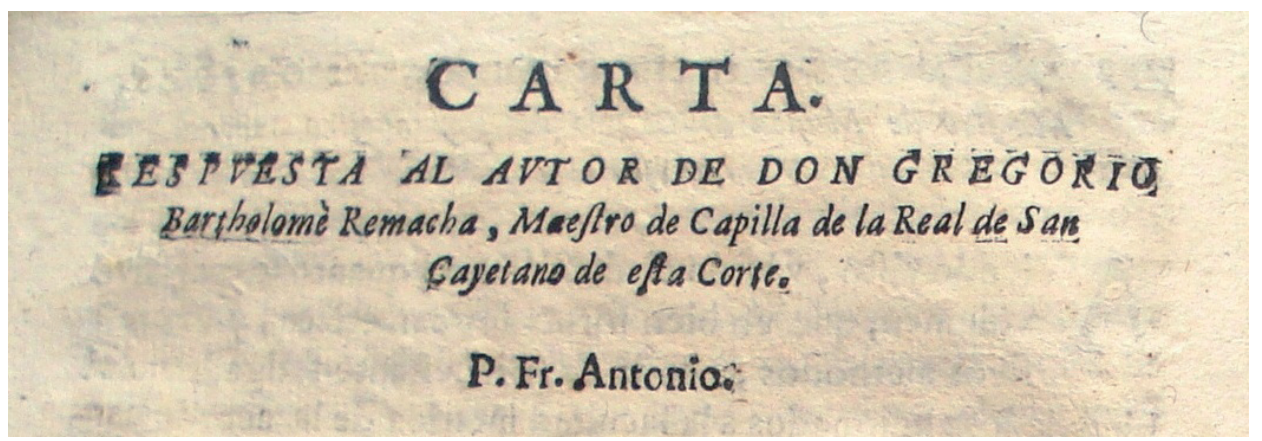

Figura 3. Detalle de la carta redactada por Gregorio Remacha a fray Antonio Martín y Coll

Apenas unos días más tarde, el 7 de septiembre, Remacha acude a la convocatoria para obtener la plaza de maestro de capilla de la catedral de Salamanca que había quedado vacante tras la muerte de Tomás de Micieces ocurrida en el mes de Mayo de $1718^{28}$. A dicha oposición asistieron trece aspirantes, según el acta de nombramiento, redactada por el entonces secretario catedralicio: Joseph Martí de la Fuente ${ }^{29}$.

En relación a la oposición magisterial en Salamanca, el sólo hecho de recordar el número de opositores da a entender que la plaza era muy codiciada por los maestros de capilla de otros centros, ya que Salamanca poseía en funcionamiento una importante universidad que tenía cátedra de enseñanza musical $^{30}$, por lo que el compositor que ejerciera el magisterio en la catedral, convenientemente lo haría en la facultad universitaria, lo que representaría no sólo un título de prestigiosa categoría como profesor universitario, sino que inexorablemente gozaría de los beneficios de dos plazas con ingreso económico.

La oposición al magisterio de capilla de la catedral salamantina tuvo dos fases, según el testimonio escrito del secretario Martí de la Fuente ${ }^{31}$, que recogió los nombres de los aspirantes que escribieron al cabildo, que en esa primera etapa sólo fueron diez: Gregorio Santiso Bermúdez, maestro de capilla de la catedral metropolitana de Sevilla; Mateo de Villa, de la de Osma; Diego de las Muelas ${ }^{32}$, de Astorga; Francisco Pascual, de Valladolid; Blas de Casseda; Fabián Clemente; Alfonso de Covaleda, músico en Zamora; Pedro Rodrigo, Lorenzo Romero y Felipe Arteaga, residentes de Madrid. Puede observarse que en esta primera etapa no aparece Remacha como aspirante a la plaza.

28 Archivo de Música de la catedral de Salamanca (E-SA). En el libro de actas capitulares cuya signatura es AC49/281 pude consultar la información referente a las últimas noticias sobre el maestro de capilla " $\mathrm{R}^{\circ} \mathrm{Dn}$. Thomás de Miciezes", que desde principios del mes de Abril de 1718 manifiesta problemas de salud. En el acta AC49/304 se da razón de la muerte del maestro Micieces, y se sabe de su entierro y testamento, en el que dejaba a su madre como única heredera.

$29 \boldsymbol{E}$-SA, AC49/325.

30 Ibídem.

$31 \boldsymbol{E}$-SA, AC49/319, Agosto de 1718.

32 Maestro de quien se conserva un villancico, Abrasados serafines, en el Archivo Musical del Colegio de Santa Rosa de Morelia (México), cuyos papeles manuscritos se localizan en la carpeta 037. 
La segunda etapa de la oposición ocurrió en el mes de septiembre; el acta ${ }^{33}$ enlista los nombres de los opositores, que se transcriben similarmente al original:

Dn. Antonio de Yanguas

Dn Joseph de Casseda

Dn Matheo de Villa Piedad

Dn Thomas Cobaleda

Dn Fabián Clemente

Dn Fermín Arizmendi

Dn Diego de las Muelas

Dn Blas de Casseda

Dn Simón de Araya

Dn Pedro Rodrigo

Dn Lorenzo Romero

Dn Pedro Felipe de Arteaga

Dn Bartholomé Remacha
Presbítero Maestro de Capilla de la Santa Iglesia Metropolitana de Santiago.

Presbítero Maestro de Capilla de la Santa Iglesia de Sigüenza.

Presbítero Maestro de Capilla de la Sta. Iglesia de Osma.

Presbítero Maestro de Capilla de la Sta. Iglesia de Zamora.

Presbítero Maestro de Capilla de la Sta. Iglesia de Ciudad Rodrigo.

Clérigo in sacris Maestro de Capilla de la Santa Iglesia de Ávila.

Clérigo de menores Maestro de Capilla de la Santa Iglesia de Astorga. Maestro de Capilla de la Santa Iglesia de Santo Domingo de la Calzada. Casado.

Maestro de Capilla de la Sta. Iglesia de León. Casado.

Músico en Madrid. Casado.

Músico en Madrid. Casado.

Músico en Madrid. Casado.

Músico en Madrid. Casado.

Como se puede constatar, "Bartholomé Remacha", que aparece curiosamente sólo como músico residente en Madrid y no con el título de maestro de capilla, finaliza la lista de opositores, lo que es comprensible siendo que él no había mandado solicitud escrita previamente; pero al mismo tiempo, llama la atención que Antonio de Yanguas, que ha sido mencionado como antecesor de Remacha en Madrid, y que para ese tiempo gozaba ya de excelente reputación, encabeza la lista, aunque tampoco él había mandado previa solicitud. Pero todo esto puede preverse revisando el documento correspondiente a la fase anterior, en el que se lee lo siguiente ${ }^{34}$ :

“[...] Y el cabildo acordó que el Sr. D $\mathrm{D}^{\mathrm{r}}$. ${ }^{\mathrm{n}}$. Thomas Antonio Núñez Flores Can[ónig]o Penitenciario Comisario de Música de d[ic]ha Sta. Iglesia se informase de la habilidad ciencia y otras calidades de d[ic]hos oppositores, y singularmente de las del Maestro de Capilla de la Santa Iglesia Metropolitana de Santiago [Antonio de Yanguas], por tenerse noticia vendría a ser Maestro de Capilla si fuese llamado. Con lo qual se feneció y levantó el Cabildo, de que doy fe y lo firme: ante mí Joseph Martín de la Fuente [...]".

Por lo que probablemente el cabildo tenía intención de contar con los servicios de Yanguas, y por tanto el ejercicio de oposición sería sólo un trámite burocrático; pero otro aspecto que ocupó mi atención

$33 \boldsymbol{E}-\mathrm{SA}, \mathrm{AC} 49 / 325$.

34 Ibíd., E-SA, AC49/319. 
mientras consultaba el acta de nombramiento citada arriba, es que el orden progresivo que describe la ubicación de los aspirantes a la plaza se organizaba atendiendo a las órdenes religiosas que poseían, colocando en último lugar a los que eran casados. Este aspecto deja notar que para esta autoridad capitular era preferible contratar clérigos.

Actualmente se conservan dos villancicos de Gregorio Remacha en el archivo musical de la catedral de Salamanca, Sacra empresa celestial, a San Cayetano, a 8 voces con violines, con fecha de 1717, y Al eco sonoro, también a ocho voces, fechado en $1718^{35}$. Es muy posible entonces que estos villancicos hayan sido enviados con el fin de obtener la anhelada plaza.

Regresando a la iglesia de San Cayetano, José Artero que publicó los estudios pioneros sobre Yanguas $^{36}$; afirma haber ido a esta iglesia madrileña, atestiguando, en 1930, que el archivo estaba inexplorado. En ese tiempo (anterior a la Guerra Civil española de 1936-1939), el archivo aún no había sido destruido, por lo que su testimonio supone una fuente de información imprescindible. Entretanto, convendrá seguir buscando otras publicaciones y posibles referencias a este mismo tema por parte de otros investigadores del primer tercio del siglo XX.

Continuando con la actividad musical de Remacha en Madrid, se puede constatar que dirigió la capilla musical de San Cayetano por lo menos hasta la Navidad del año de 1730, lo cual se puede verificar en otros impresos de letras de villancicos que se cantaron en esta iglesia en los maitines de las navidades de los años 1715, 1723, 1725, 1726, 1727, 1728, y finalmente 1730, respectivamente, ejemplares que se conservan en la Sala Cervantes de la Biblioteca Nacional de España ${ }^{37}$.

Conviene señalar que aunque estos impresos no contengan las partes musicales, dan a saber que durante los más de quince años que estuvo dirigiendo la capilla musical del templo de San Cayetano, hogar de la orden de Teatinos, Gregorio Remacha debió componer villancicos para la Navidad, también para el Corpus Christi - por el peso de esta festividad-, Reyes, y para la festividad propia de San Cayetano, por lo que se podría calcular que el número de estas composiciones que se le encomendaban, habría ascendido aproximadamente a un centenar de villancicos, tan sólo hablando de los de Navidad. Pero la realidad es que la cantidad de los que sobreviven (y de los que he logrado localizar), es mínima.

En el ámbito madrileño, su magisterio de capilla fue bastante regular y duradero, conservándolo, por lo menos, quince años. Remacha opositó entonces a la plaza de maestro de capilla de la castellana catedral de Valladolid, una vez fallecido Francisco Vidal, titular de dicha plaza, en diciembre de $1730^{38}$. A la oposición asistieron ocho aspirantes ${ }^{39}$ : Andrés Algarabel, maestro de capilla de la catedral de Segovia; Adrián González Gámiz, de la de El Burgo de Osma (Soria); Domingo Tejedor [sic. Teixidor], de la de Lérida; Agustín Gámiz de Salazar, racionero organista en la catedral de Zamora; Tomás Barcenilla, organista de Valladolid; y Manuel Paradís, José Mir y Llusá, y Gregorio de Bartolomé Remacha, estos tres últimos

35 GARCÍA FRAILE, 1981: 447.

36 ARTERO, I, 1930:156-157.

37 GUILLÉN BERMEJO, y RUIZ DE ELVIRA SERRA, 1990: 761, 789, 796, 804, 808, 813 y 822.

38 LÓPEZ CALO, vol. VII, 2007: 220.

39 LÓPEZ CALO, vol. II, 1989: 176. 
residentes en Madrid. Finalmente, el maestro Andrés Algarabel y Arroyo fue quien llevó la plaza, con la posesión de la ración entera correspondiente al magisterio de capilla el 24.04.1731. Resulta llamativo que no se conserve ninguna obra de Remacha en el nutrido archivo musical de la catedral de Valladolid ${ }^{40}$.

Tras este nuevo intento por ocupar el magisterio de capilla de uno de los centros catedralicios de más importancia en España, sobre todo en lo que respecta al aspecto musical, Gregorio Remacha regresó a dirigir la capilla musical de San Cayetano y pasar sus últimos meses al frente de dicha agrupación.

La siguiente noticia de cierta relevancia respecto a este compositor es su nombramiento como maestro de capilla en la Insigne Colegial de Toro (Zamora) ${ }^{41}$ en Noviembre de 1731. Afortunadamente he podido localizar y consultar el acta capitular de dicho nombramiento, en la que se manifiestan de manera clara y precisa las razones por las cuales se elige al maestro Remacha para el magisterio de capilla, así como sus obligaciones y percepciones salariales. En vista de la importancia de este documento para el presente trabajo, lo reproduzco íntegramente:

"Acuerdo para admisión del M[aest]ro de Capilla ${ }^{42}$.

En la ziu[da]d de Toro a v[ein]te y uno de Nov[iemb]re año de mil Set[eciento]s y treinta y uno estando en la sala Capitular los Señores Avad y Canónigos desta ynsigne collejial que auajo firmaran para tratar y conferir las cosas tocantes al Seruizio de Dios n[uest]ro señor vien y aum[en]to de esta ynsigne ig[lesi]a, por ante mí Manuel Cauero n[otari]o y s[ecreta]rio deste Cauildo el señor D ${ }^{r}$. Don Pedro Vidal como tal avad propuso a d[ic]hos señores que rrespecto heran notiziosos que el majisterio de Capilla desta ynsigne ig[lesi]a se allaua vaco porque el que auia se auia despedido y estar admitido por tal en la santa ig[lesi]a Catedral de la $z$ [iuda]d de Zamora ${ }^{43}$ por cuio motiuo se alla esta ynsigne ig[lesi]a sin m[aest]ro de Capilla que rrija y govierne la de los m[aest]ros de ella y que siendo zierto esto como tanvien lo hera que Don Gregorio Remacha que rreside en la uilla y corte de Madrid auia escripto Carta al Cauildo a q[uie]n la mostro suplicando se le admitiese por tal $\mathrm{m}$ [aest]ro de capilla y que rrespecto d[ic]ho Don Gregorio antes de aora se auia opuesto a este majisterio y quedado con el luzim[ien] to que sauian $\mathrm{d}$ [ic] hos señores quienes auiendo visto $\mathrm{d}[\mathrm{ic}]$ ha proposizion $=$ Dijeron que hera todo zierto por lo qual todos unánimes y conformes nemine discrepante dieron su voto admitiendole al d[ic]ho Don Gregorio al refer[i]do majisterio como con efecto quedo admitido con tal que el susod[ic]ho a de ser de su obligaz[ió]n enseñar la música a todos los muchachos y mozos de coro que asisten en esta ynsigne ig[lesi]a y a el sochantre de ella dandole su lecsion cada día y al d[ic]ho m[aest]ro se le señala por su salario noventa rr[eale]s cada mes y media carga de trigo que es lo mismo que se a dado a los demas sus antezesores acudiendole con todos los

40 LÓPEZ CALO, vol. III, 2007.

41 La Colegial de Toro que se localiza en la provincia de Zamora, España. Es uno de los templos más preciosos de la arquitectura románica; se comenzó a construir en el siglo XII y está consagrado en honor de Santa María la Mayor. Tiene la categoría de colegial o colegiata porque aunque no tiene sede obispal, si la ocupaban, o bien una orden de clérigos regulares o, como sucedía en tiempos más cercanos, con abad y canonjía. En términos generales es similar a una catedral excepto por no tener obispo. Sin embargo, hoy en día no quedan ya órdenes regulares en España, por lo que la condición de colegiata es sólo un recuerdo de tiempos pasados.

42 Archivo Histórico Diocesano de Zamora, Sección Archivos Parroquiales, 227.2/libro 48, Folio 240 (parte posterior). Es importante aclarar que en la actualidad el Archivo documental de la Colegiata de Toro se encuentra en el Archivo Diocesano de Zamora.

43 Gregorio Remacha sucedió al maestro Don Manuel Agullón y Pantoja, como se puede observar, en el folio 270 del libro 48 del Archivo Histórico Diocesano de Zamora, en que se expone un memorial escrito por el mencionado Agullón y Pantoja que aún ejercía el maestrazgo de capilla en la Colegial de Toro en Noviembre de 1730. Veáse, CUADRADO GARZÓN, 1996. 
demas emolumentos que por tal $\mathrm{m}$ [aest]ro le tocan y deua lleuar y pertenezer guardandole los demas ministros de esta Capilla todos los honores honrras y prerrogativas y preeminenzias que a los demas y así lo acordaron y firmaron de que doy fe y firme. $=\mathrm{D}^{\mathrm{r}}$. D. Pedro Vidal / Pedro Álvarez Gutierrez / Diego Vitoria y Ribera / D . Thomas Joseph de Zerar Ochoa / D. Ant[oni]o de Riuera / D. Joseph Sanchez / D . Fran[cis]co Bernal / D. Nicolas de Monroy / D. Nicolas Ygnacio de Villegas / Manuel Cauero".

Aquí queda patente que Don Gregorio, tenía las explícitas instrucciones de ejercer como maestro, es decir, estar a cargo de la enseñanza tanto de los mozos de coro como del sochantre. En cuanto a los fondos musicales de la colegiata de Toro, no se conserva archivo musical de dicha iglesia ${ }^{44}$. Lamentablemente, no se conocen bien las causas.

No existen tampoco catálogos o estudios musicales publicados en torno a esta iglesia colegial, de modo que, tras las pequeñas consultas documentales que pude realizar en este lugar, es probable que Remacha permaneciera en el puesto al menos una década, sin encontrar la fecha en la que deja su magisterio en Toro. Durante el período de 1732 a 1740 no se hace mención, en las actas capitulares, de asuntos relacionados con el maestro de capilla, con lo que presumiblemente su trabajo debió ser bastante estable y sin inconvenientes.

Respecto a Toro, hasta el momento no he encontrado evidencia que confirme que en esta colegiata hayan sido impresos pliegos de letras de villancicos, los cuales podrían constituir una importante herramienta metodológica alternativa ${ }^{45}$. Esperemos que el archivo musical de la colegiata de Toro sólo esté extraviado y que, en un futuro próximo, se dé a conocer.

Sobre la actividad compositiva relativa a los villancicos en la Insigne Colegial de Toro he localizado una única referencia: el libro de cuentas de este templo referente a los años 1731 y 1732 en que, a la vez que se especifica el salario pagado al maestro de capilla Gregorio Remacha, en diciembre de 1731, se da cuenta que el cabildo pagó a Antonio de Rivera el salario correspondiente de los meses de diciembre de 1731 y Febrero de 1732 por el concepto de los villancicos de Navidad $^{46}$.

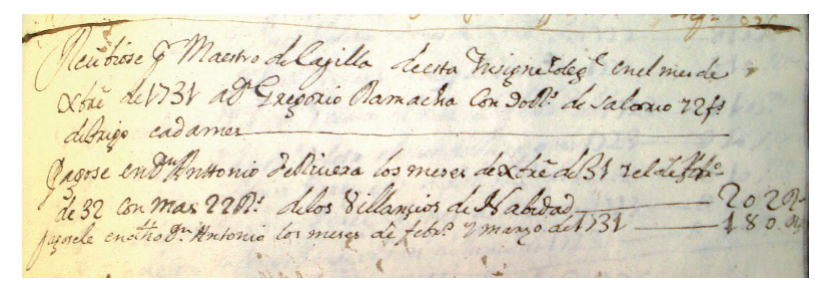

Figura 4. Detalle de recibo de pago al maestro de capilla Archivo Histórico Diocesano de Zamora, 227.2/libro 31

44 Según indicación expresa del actual archivero del obispado de Zamora, José Carlos de Lera Maíllo, a quien agradezco la información.

45 En Zamora no se han conservado villancicos impresos anteriores al siglo XIX, y tampoco han sobrevivido en Toro. MARTÍN VÁZQUEZ, 62, 2007: 75-96.

46 Archivo Histórico Diocesano de Zamora. Sección Archivos Parroquiales, 227.2/ libro 31. 
Lo anterior permite plantear algunas hipótesis: en primer lugar, que el mencionado Antonio de Rivera haya sido el posible autor de las letras para los villancicos de la Navidad de 1731 y como consecuencia, que Remacha compusiera la música para dichas letras; o bien, que recién llegado el maestro de capilla fuese Rivera quien se hubiera encargado de musicalizar los villancicos de esa festividad. También cabría posibilidad de que fuera el impresor. Conviene, pues, profundizar en el futuro sobre este Antonio de Rivera.

Después de siete años desempeñando Remacha el magisterio de capilla de la colegiata de Toro, en la vecina actual provincia de León, de acuerdo con datos publicados por A. Martín Moreno, a la muerte del maestro de capilla Simón de Araya, en 1738, el cabildo leonés no se preocupó de cubrir la plaza de inmediato, sino que se limitó a invitar a los maestros cercanos para las principales fiestas, entre ellos a Gregorio Remacha ${ }^{47}$. Sin embargo, en los catálogos musicales publicados de la catedral leonesa, uno de Emilio Casares (más bien un inventario detallado) ${ }^{48}$, y otro (mucho más minucioso) de Samuel Rubio Álvarez ${ }^{49}$, no se observa la existencia de obra alguna de Remacha.

Por otra parte, dos años después, el maestro de capilla de la catedral de Ourense, Tomás Clemente Moscoso, renuncia a su plaza, siendo candidatos para la provisión de ésta: Gregorio Remacha, maestro de capilla de la colegiata de Toro y Gaspar Vázquez, que antes había sido maestro de capilla en la pequeña localidad castellana de Villagarcía de Campos (Valladolid). Sin embargo, ninguno de los dos se presentó a los ejercicios de oposición ${ }^{50}$, que consistieron en: una prueba de composición en 24 horas y después cada aspirante debía ensayar su obra con el coro y en la capilla. El 30.06.1740 habían realizado dichas pruebas Jerónimo Romero, un exseise de Toledo, Andrés Bas, y Antonio Guadarrama, que resultó elegido para el puesto.

El testimonio anterior deja en claro que para los compositores de la época era importante "estar al día" con lo que pasaba a sus alrededores; Gregorio Remacha figuraba como candidato para ocupar el magisterio de capilla de la mencionada catedral gallega, lo cual evidencia el interés del compositor por la búsqueda, seguramente, de mejores condiciones de trabajo.

Para los fines metodológicos de este ensayo, ha sido elemental plantear un bosquejo del recorrido artístico de Remacha, en gran parte, delineado por las convocatorias para ocupar la plaza de maestro de capilla de diferentes centros. En este último caso sorprende saber que finalmente él no asistió a la señalada oposición, quizá porque ya no tenía planes de moverse hacia la región gallega.

Los datos que se conocen hasta ahora sobre la estancia de Remacha en Toro culminan en esta fecha.

Los aspectos musicales de esta iglesia no se han estudiado, y ni siquiera se conocen los nombres de los músicos que labraron el quehacer musical durante siglos, ni quiénes ejercieron el magisterio de capilla antes de Remacha, si exceptuamos a Manuel de Agullón, su antecesor en el magisterio de capilla, y quiénes le sucedieron.

47 MARTÍN MORENO, 1985: 122.

48 CASARES RODICIO, 67, 1980:7-88.

49 RUBIO ÁLVAREZ, 2005.

50 GARBAYO MONTABES, 2004: XLII. 
En, al menos una década, en Toro, ¿cuántas obras habrá producido Gregorio Bartolomé Remacha?, ¿cuántos villancicos?, algunas de las obras conservadas en el Archivo Musical del Colegio de Santa Rosa de Morelia (México), ¿procederán de la colegiata de Toro? Por lo menos dos de ellas exhiben las siguientes fechas de copia: 1738 y 1741. Pero ante las enormes lagunas documentales no se puede conjeturar mucho.

La siguiente noticia de Gregorio Remacha la he localizado (también de manera impresa), en Alcalá de Henares. En el siglo XVI, el cardenal Cisneros obtuvo para esta iglesia el rango honorífico de "Magistral", que al menos hasta el siglo XVIII, fue la única en España con esta categoría; sin embargo, no poseía el título de catedral.

Músicos como Andrés Lorente $(* 1624 ; \uparrow 1703)$, autor del célebre tratado de teoría musical, El Porqué de la Música, que había estado alrededor de 50 años al servicio de la Magistral, así como Antonio Rodríguez de Hita $(* 1722 ; \dagger 1787)$, destacado teórico y maestro de capilla, confeccionaron todo un ecosistema para el arte musical ${ }^{51}$.

Gregorio Remacha fue maestro de capilla de la Santa Iglesia Magistral de San Justo y Pastor de Alcalá de Henares, como se puede leer en el interior del impreso titulado:

"Laudatorio Panegyrico-Músico: que sobre el punto sonoro [...] Cantò Fray Migvel Landivar Cavallero, $[\ldots]^{\prime, 52}$,

en el que se encuentra una carta respuesta al autor de Gregorio Remacha, quien se presenta de esta manera:

"Maestro de Capilla, que fuè en la Real de San Cayetano de Madrid: después en la muy Insigne Colegial de la ciudad de Toro: y al presente en la Santa Magistral de San Justo, y Pastor, de esta ciudad de Alcalá de Henares".

Este impreso está fechado en 1745 y contiene una carta de Remacha a Landívar, en la que se observa una reseña pormenorizada y elocuente de las dotes interpretativas de este destacado — según Remacha—, cantante de la época.

El documento citado informa, de voz del propio compositor, que era maestro de capilla en esta iglesia. Sin embargo, para tener fecha precisa de su nombramiento es necesario recurrir a las actas capitulares correspondientes. Pero los sucesos de 1936 también afectaron negativamente a la Magistral de Alcalá de Henares.

Según testimonio del padre Juan Miguel Prim Goicoechea, encargado del archivo de la ahora catedral de Alcalá de Henares, al día de hoy sólo se conservan las partidas de defunción, bautizo o matrimonio, pero en series incompletas; el resto de documentación, incluyendo el archivo musical, perecieron en los actos bárbaros de 1936 a $1939^{53}$.

51 RECASENS, "Rodríguez de Hita”, Músicos de la Magistral, http://www.catedraldealcala.org (Acceso: 11.10.2009).

52 Este impreso se localiza en $\boldsymbol{E}-\mathbf{M n}$, Sala Barbieri, con signatura: MC/3878/16.

53 Los datos referentes a los atentados en la ahora catedral de Alcalá de Henares, así como sobre el estado actual del archivo musical, pude recopilarlos en una entrevista con el sacerdote J. M. Prim Goicoechea por correo electrónico con fecha 05.12.2008. 
En cuanto a la fecha de nombramiento de Remacha en Alcalá, fue menester seguir el rastro de otros músicos que figuraron en dicho templo, como el caso de Antonio Rodríguez de Hita ${ }^{54}$, evidentemente más joven que Remacha, pero que era originario de esta ciudad, además de gran músico y tratadista, que gozó de buena reputación en el ámbito musical ibérico. A temprana edad (diez años), ingresó en el colegio de seises de la Iglesia Magistral, estudiando gramática y música con Francisco Moratilla ${ }^{55}$. Fue maestro de capilla de la Magistral de Alcalá de 1738 a 1744. En ese mismo año gana la oposición para obtener la plaza de maestro de capilla en la catedral de Palencia. ${ }^{56}$

Gracias a los datos anteriores se puede deducir que Remacha trabajó en Toro aproximadamente hasta 1744 y (aunque no quede claro si por nombramiento o por oposición), obtuvo el cargo de maestro de capilla en la Santa Iglesia Magistral de San Justo y Pastor entre 1744 y 1745, año de publicación del Laudatorio Panegyrico-Músico... en que el propio Remacha daba brevísima cuenta de su curriculum vitce.

La existencia impresa de las letras de villancicos, en esta ocasión referentes a la Santa Iglesia Magistral de Alcalá de Henares, vuelve a convertirse en herramienta principal de esta investigación, ya que estas ediciones informan que en los años 1753 y 1754 Gregorio Remacha compuso la música para los villancicos de los maitines de Navidad, siendo maestro de capilla de la mencionada iglesia magistral.

Este es el último dato que he logrado localizar hasta la fecha, de la vida activa del maestro Gregorio Bartolomé Remacha, pero no se puede precisar con exactitud hasta cuándo trabajó en Alcalá y si ejerció el cargo hasta su muerte. Tampoco he localizado líneas secundarias que muestren los nombres de los maestros que sucedieron a Remacha en la Iglesia Magistral.

Por otra parte, el Archivo Musical del Colegio de Santa Rosa en Morelia conserva un villancico, Venid al Combite, en que se observa la fecha de copia en 1760. La cuestión es si ésta puede ubicarse en las obras tardías de Remacha, o incluso si se fechó o no en vida del compositor.

Con la serie de inconvenientes que han sido atestiguados, es comprensible que hasta ahora no se conozca con precisión la fecha y lugar de nacimiento este compositor, dónde y con quién tomó sus primeras lecciones de música, y ni siquiera su fecha de muerte. En España, en una pequeña población llamada Cimballa ${ }^{57}$ la calle principal lleva el nombre de Gregorio Remacha. ¿Tendrá Cimballa una relación directa con el maestro de capilla en cuestión?, ¿nació o fue bautizado ahí Remacha? Por ahora, la respuesta a estas interrogantes ha de quedar en el aire, hasta que sea posible realizar una búsqueda de primera mano en los archivos de esta comunidad.

Una última y tangencial directriz, que aproxima a dilucidar posibles lazos familiares, es la relación con otros músicos que llevan el mismo apellido. A finales del siglo XVIII y primer tercio del siglo XIX, el personaje más significativo es Miguel López Remacha.

54 RECASENS, vol. 21, 2001a: 503-504. RECASENS BARBERÁ, 2001b.

55 Francisco Moratilla es uno de los compositores que más nutren el Archivo Musical del Colegio de Santa Rosa, en Morelia (México), y en quien Miguel Bernal Jiménez vio la mano de un gran maestro. En 1939, Bernal publicó el catálogo del mencionado archivo, cuando sólo tres años antes el archivo de la Magistral de Alcalá había sido incendiado.

56 LÓPEZ CALO, vol. 2, 1980: 123-124.

57 Cimballa es un pequeño municipio en la comunidad de Aragón, provincia de Zaragoza, en la comarca de Calatayud, de poco más de un centenar de habitantes, http://www.pueblos-espana.org/aragon/zaragoza/cimballa/mapa/ (Acceso: 08.02.2009). 
Para establecer un contexto formal en torno al primer músico, Miguel López Remacha, conviene remitir al matrimonio del notable compositor del siglo XVIII, Félix Máximo López, quien se casa secretamente y por poderes en la Iglesia Magistral de Alcalá de Henares con María Dominga de Bartolomé Remacha el 29.06.1764, y dos años más tarde, de manera pública, en la Iglesia de San Ginés en Madrid ${ }^{58}$.

Inmediatamente es notable que el apellido compuesto de María Dominga de Bartolomé Remacha corresponde con el de nuestro compositor, lo que invita a suponer que pudiera tratarse de una hija de Gregorio (de) Bartolomé Remacha, invitación refrendada por la coincidencia del lugar y fecha de su primera boda, Alcalá de Henares en 1764, último lugar y época de la actividad del maestro de capilla. De poderse iluminar esta sospecha, se tendría la oportunidad de ver el desarrollo del linaje musical de Gregorio Remacha.

Regresando al matrimonio entre Félix Máximo López y María Dominga, es preciso señalar que de esta unión nace Miguel López Remacha $(* 1772 ; \uparrow 1727)$, considerado uno de los músicos más destacados de España en aquella época, tanto como compositor de obras sacras y operísticas, como tratadista (publicó una obra relativa a la composición y otra al solfeo), además de ejercer como primer tenor de la Capilla Real de Madrid ${ }^{59}$.

Tras la necesidad de esclarecer los posibles vínculos entre Miguel López Remacha y Gregorio de Bartolomé Remacha era imprescindible consultar las fuentes documentales de primera mano del archivo de la iglesia parroquial de San Ginés en Madrid $^{60}$.

Según el acta o partida matrimonial de Félix Antonio Máximo López, hijo de Antonio López y Basilia Crespo, éste se unió, por el ritual romano, con Dominga Victoria María de Bartholomé, hija de Juan de Bartholomé y de Juana de Zahonero ${ }^{61}$. Queda claro, por tanto, que Gregorio Bartholomé Remacha no tenía, al menos, relación consanguínea directa (en primer grado) con Dominga.

También llama la atención el hecho de que el apellido Remacha no figura en el de-Juan de Bartholomé y tampoco en el de su hija Dominga Victoria. En consecuencia, también consulté la partida bautismal de Dominga Bitoria [Victoria] María ${ }^{62}$, en la cual tampoco figura el apellido Remacha. Pero ¿por qué razón el músico y presbítero Miguel López [Remacha] siempre fue conocido y firmó con el apellido Remacha y no con el de Bartholomé como oficialmente correspondería?

Constatando también la partida bautismal de Miguel López, cuyos nombres de pila eran Miguel Estanislao Bruno ${ }^{63}$, bautizado también en San Ginés el 08.05.1772, puede leerse que el nombre de su madre, María Dominga Remacha, está tachado, y sobrepuesto el de Dominga Victoria María Bartholomé y Zahonero. El documento contiene además una nota aclaratoria en que se manda borrar el apellido Remacha

58 COBO, Alberto: La primera Zarzuela moderna, http://www.superopera.com/zarzuela2.htm (Acceso: 16.04.2009).

59 HOWELL, vol. 15, 2001: pp.174-175.

60 Agradezco la generosidad de Luis López Ruiz, a través de quien fue posible la consulta y reproducción digital de estas valiosas fuentes documentales en el archivo histórico de la iglesia parroquial de San Ginés, en Madrid.

61 Archivo Histórico de la Iglesia Parroquial de San Ginés, libro 15, fol.168.

$62 \mathrm{Ibíd}$., libro 36, fol.366v. Así aparece el nombre de ella; es evidente que en esa época los notarios no eran tan cuidadosos con el orden y ortografía de los nombres de pila.

63 Ibíd., libro 40, fol.105. Curiosamente, Miguel López Remacha nunca utilizó sus otros nombres Estanislao Bruno, como tampoco el apellido Bartholomé. 
quedando el de Bartholomé y Zahonero. Esta enmienda es ordenada por "el Sr. Lic. Dn. Alonso Camacho, Inquisidor Ordinario y Vicario de la villa de Madrid", el 03.10.178364.

Concluyendo, sólo se puede constatar la misteriosa circunstancia que significó el apellido Remacha en esta familia de músicos, quedando aún en el aire el porqué del uso de éste, o si fuera el apellido materno del padre de Dominga, Juan Bartholomé, y que curiosamente su nieto, Miguel López Remacha, siguió utilizando aún por encima de los de Bartholomé y Zahonero. Por el momento, no es plausible que Gregorio Remacha haya sido abuelo de Miguel ${ }^{65}$.

\section{OBRAS MUSICALES CONOCIDAS}

El hecho de tener papeles de música de Gregorio Remacha en México y España hace posible su estudio, y consecuentemente permite vislumbrar las características principales de su estilo, sus rasgos distintivos más frecuentes o, por el contrario, la diversidad de recursos compositivos que emplea.

Se conservan obras suyas en castellano (villancicos), y también obras en latín.

Contrariamente al amplio período de tiempo que Gregorio Bartolomé Remacha ejerció el magisterio de capilla en San Cayetano (Madrid), Toro (Zamora) y Alcalá de Henares (Madrid), que aproximadamente abarca unas cuatro décadas, el número de obras musicales que hasta ahora he logrado localizar apenas supera las dos decenas, considerando obras completas e incompletas.

Por otra parte, las fuentes que conservan la música de Remacha están dispersas, principalmente en España, y en México, rasgo que confirma que la circulación ${ }^{66}$ de obras musicales estaba muy activa durante el virreinato.

\section{FUENTES MUSICALES}

Son hasta ahora diez archivos musicales en los que he identificado obras bajo la autoría de Remacha: el archivo musical del Colegio de Santa Rosa de Morelia (8); el archivo musical de la catedral de Morelia (1); el archivo musical de la catedral de Puebla (1)*, en México; la Real Biblioteca del Monasterio de San Lorenzo de El Escorial (3); la Real Biblioteca de Palacio (2); la Biblioteca Nacional de España (2); el archivo de la catedral de Salamanca (2); la Biblioteca de Catalunya (1); el archivo musical de la Abadía de Montserrat

64 Idem. El aspecto cronológico también es significativo, ya que Dominga murió en 1780.

65 En la partida bautismal de Dominga Victoria María Bartholomé, Archivo Histórico de la Iglesia Parroquial de San Ginés, op.cit., se puede observar el origen de su padre Juan Bartholomé, que era natural de Pozuel de Ariza, que en aquel entonces pertenecía al obispado de Sigüenza, en la provincia de Zaragoza y comarca de Calatayud, es decir, no muy lejos de Cimballa, el pueblo que lleva el nombre de Gregorio Remacha en una de sus calles. La incógnita ahora es si entre Juan Bartholomé y Gregorio Bartholomé Remacha haya algún tipo de parentesco. Pero esto excede, por ahora, nuestras posibilidades de estudio.

66 EZQUERRO ESTEBAN, 2010: pp. 59-104. 
(3); y el archivo de música de la catedral metropolitana de Santiago de Compostela (1)*, en España ${ }^{67}$. A continuación se presentan los títulos de las obras localizadas hasta ahora ${ }^{68}$ :

01.- El archivo musical del Colegio de Santa Rosa, Conservatorio de las Rosas (en Morelia, Estado de Michoacán, México), es el epicentro de la obra conservada de Gregorio Bartolomé Remacha, con un total de ocho villancicos, rasgo paradójico ya que, como se ha visto, este compositor no estuvo activo en la Nueva España.

1. Venid al combite, a 4, con violines.

1760

Sig. 060

2. A esta espiga tierna, a 4, con violines.

Sig. 061

3. Luz Gloriosa, a 4, con violines.

Sig. 062

4. Sobre el pan de los cielos, a 7, con violines.

5. Al sol entre sombras, a 8, con violines.

Sig. 064

6. Ay dulce amor, a 4, con violines.

Sig. 065

7. Bibientes pasajeros, a 7, con violines.

Sig. 066

8. Bagel pues que felice, a 4, con violines.

02.- Archivo de música de la catedral de Morelia (Estado de Michoacán, México):

1. Latatus sum, a 8, con violines y oboe.

Sig. Carpeta $409 \mathrm{~N}^{\circ} 1$

03.- Archivo de música de la catedral de Puebla (Estado de Puebla, México). En el manuscrito se atribuye la obra al maestro Manuel Remacha; pero hasta ahora no se conoce ningún compositor del siglo XVIII con ese nombre de pila, debido a lo cual este manuscrito — con obvias reservas- encabeza la lista de obras de Gregorio Remacha con difícil atribución.

1. Salve Regina.

Sig. Música Leg. 18 Núm. 10

04.- Real Biblioteca del Monasterio de San Lorenzo el Real de El Escorial (Madrid) (E-E):

1. Ave Maris Stella, a 8.

2. A Belén Corte del Niño, a 8 .

3. Oíd Montes, a 8.
Sig. $77-7$

Sig. $88-20$

Sig. $77-8$

05.- Real Biblioteca de Palacio. Fondo del Monasterio de las Descalzas Reales, de Madrid (E-Mp):
1. Letanía a Nuestra Señora, a 4.
(C)
Sig. $93 /(7)$
2. Salve Regina, a 4.
Sig. 93

06.- Biblioteca Nacional de España, en Madrid $(\boldsymbol{E}-\mathbf{M n})$ :

$$
\text { 1. Misa, a } 8 \text { y a } 4 \text {. }
$$

Sig. $4937 / 27$

67 He asignado un asterisco, *, a las composiciones de difícil atribución.

68 A manera de listado señalo los títulos de las obras de Remacha en los diez fondos musicales citados, siguiendo los siguientes criterios: Título de la obra; categoría, es decir, que si está completa aparecerá (C), o si está incompleta (I); fecha de copia en el manuscrito; y signatura actual de acuerdo a los códigos de cada fondo. 

2. Letanía a Ntra. Señora, a 8, con violines.
(C)
1745
Sig. 4937/23

07.- Archivo de música de la catedral de Salamanca $(\boldsymbol{E}-S A)$ :

1. Sacra empresa celestial, a 8, con violines.

(C)

2. Al eco sonoro, a 8.

(C) 1718

Sig. AM.54.27

08.- Archivo de música de la catedral de Santiago de Compostela $(\boldsymbol{E}-S C)$ :
1. Soberano Señor Sacramentado.
(C)
Sig. $N^{\circ} 2137$ legajo 146.

Esta última obra se considera de difícil atribución. Todas las partes se presentan duplicadas; y en una de las portadillas se anota el nombre Miguel López [Remacha] con otra tinta. La dotación instrumental que presenta dicha copia corresponde más bien a la época de Miguel López Remacha: Bajo Obligado; Tiple, Tenor, Bajo; flauta, clarinete 1, clarinete 2, trompa 1, trompa 2, violín 1, violín 2, viola, violonchelo-contrabajo. En el catálogo realizado por J. López Calo sobre este fondo, solamente se atribuye a "Remacha", sin nombre de pila ${ }^{69}$.

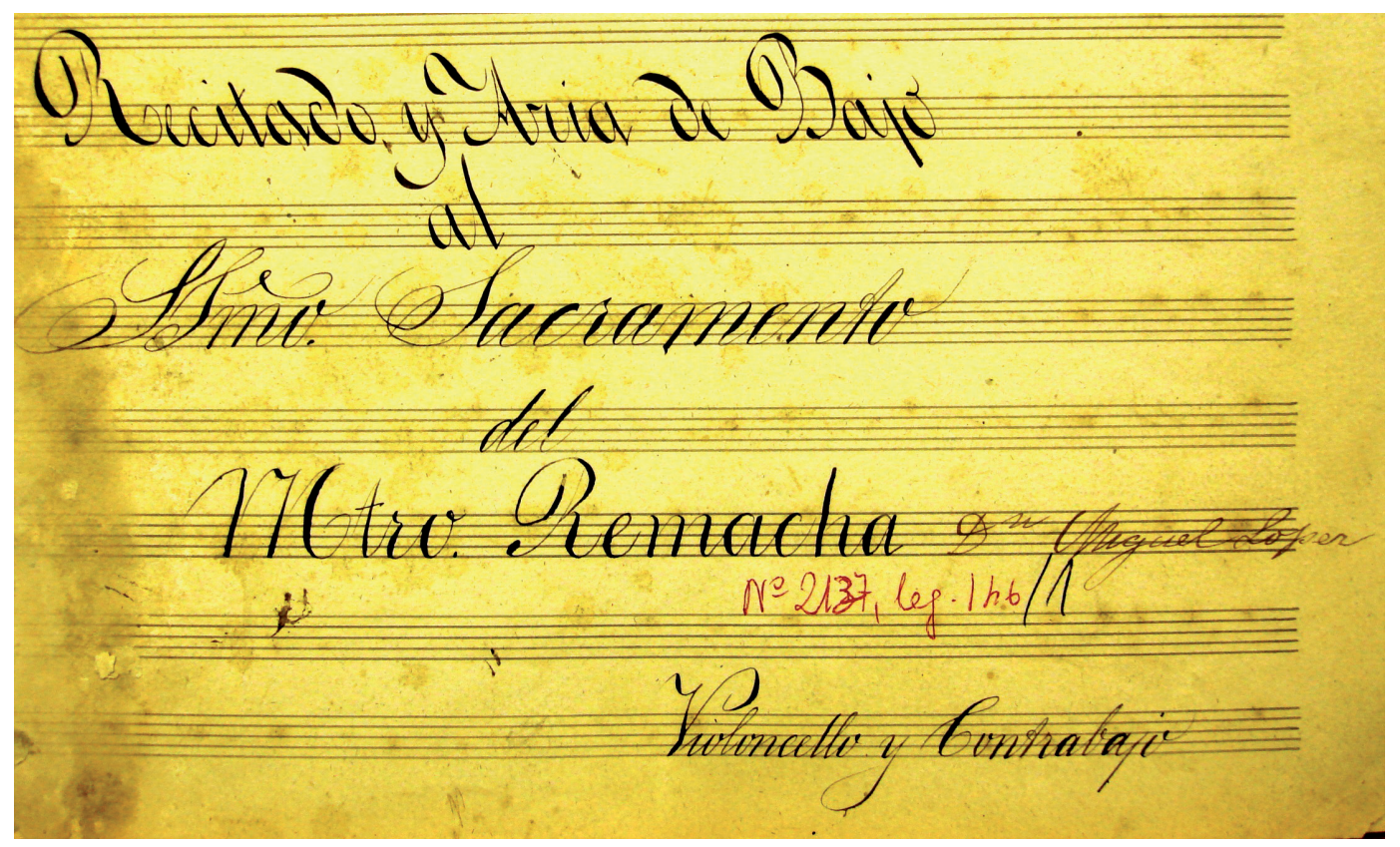

Figura 5. Detalle de la portadilla de Soberano Señor Sacramentado. Sig. ํ2137, legajo 146

69 LÓPEZ CALO, 1972: 293. 
09.- Biblioteca de Catalunya $(\boldsymbol{E}-B b c)$ :

1. Laudate Dominum omnes gentes, a 7.

Sig. M 759

10.- Archivo musical de la Abadía de Montserrat $(E-M O)$ :

1. Parce mihi, a solo de Contralto, con violines y flautas. (C)

Sig. M 3245

2. En confusa horrible guerra, a 4, con violines.

(C) $\quad 1730$

Sig. M 3925

3. Secuencia Lauda Sion, a 8.

(C) $\quad 1718$

Sig. M 4417

\section{CONCLUSIONES}

El compositor Gregorio Bartolomé Remacha ( $f$. 1715-1754) ejerció el papel de maestro de capilla en la Real Iglesia de San Cayetano, de Madrid, al menos desde 1715 hasta 1731, en que fue nombrado maestro de capilla de la colegiata de Toro (Zamora), desempeñando el cargo probablemente hasta 1744. A partir de 1745 está registrado como maestro de capilla de la Santa Iglesia Magistral de San Justo y Pastor de Alcalá de Henares, recogiéndose la última referencia de este músico en el año de 1754, en que aún ejercía el magisterio en dicho templo.

El argumento más poderoso que acentúa el hecho de que este músico (cuya longeva carrera artística rebasa las cuatro décadas) permanezca desconocido en el entorno de la musicología hispanoamericana, se debe a los incendios provocados en la Guerra Civil española, tanto en San Cayetano como en Alcalá de Henares, que consumieron su trabajo de más de veinte años de labor compositiva. El fondo musical de la colegiata de Toro se encuentra perdido. Puede sumarse al trágico destino de la obra de éste, y otros tantos músicos, el conocido incendio del Real Alcázar de Madrid en la Navidad de 1734, en que probablemente se encontraran obras de Gregorio Remacha, ya que él trabajaba habitualmente en el entorno de las capillas reales en tiempo de Felipe V.

Hasta el día de hoy he logrado identificar veintidós obras de este maestro de capilla, ubicadas en diversos archivos y bibliotecas de España y México, siendo el archivo musical del Colegio de Santa Rosa, Conservatorio de las Rosas (en Morelia, Estado de Michoacán, México), el epicentro de la producción localizada de Gregorio Remacha. Y aunque algunas fuentes han atribuido el florecimiento artístico de este músico en la antigua ciudad de "Valladolid de Michoacán", hoy Morelia, por lo menos se ha logrado demostrar que Gregorio Remacha no tuvo actividad presencial en dicha ciudad, aunque sí se conservan en este fondo el mayor número de sus obras hasta hoy conocidas. Merece la pena que este repertorio se dé a conocer en sus diferentes vertientes, sacando a la luz ediciones críticas en partitura de su música, que pongan al alcance de los intérpretes de la actualidad este rico material, realizando conciertos, y proponiendo trabajos de grabación de las obras que conforman los tesoros musicales novohispanos ${ }^{70}$.

70 Durante el año 2010, en Morelia, Michoacán, se realizaron cuatro conciertos, en el marco del I Coloquio de Musicología de Morelia, X Festival Arte Joven, y el XXII Festival Internacional de Música de Morelia "Miguel Bernal Jiménez", cuyos pro- 


\section{BIBLIOGRAFÍA}

ALONSO, Celsa, "Remacha, Gregorio", Diccionario de la Música Española e Hispanoamericana, tomo 9, Emilio CASARES ed., Madrid, SGAE, 2002: 97.

ARTERO, José, "Francisco Antonio de Yanguas”, España Sacro Musical, I (15.01.1930): 156-157.

BERNAL JIMÉNEZ, Miguel, El Archivo musical del Colegio de Santa Rosa de Santa María de Valladolid, Siglo XVIII, Morelia, Morelia Colonial, Sociedad Amigos de la Música, 1939.

CALDERÓN ALCÁNTAR, Edgar Alejandro, Villancicos de Gregorio Remacha en el Colegio de Santa Rosa, Tesis de Licenciatura inédita, Conservatorio de las Rosas, Morelia, Michoacán, (México), 2010.

CARREÑO, Gloria, El Colegio de Santa Rosa María de Valladolid 1743-1810, México, Universidad Michoacana de San Nicolás de Hidalgo, col. "Historia Nuestra", 1979.

CASARES RODICIO, Emilio, "La música en la Catedral de León: Maestros del siglo XVIII y catálogo musical”, Archivos Leoneses: revista de estudios y documentación de los Reinos Hispano-Occidentales, 67 (1980): 7-88.

COBO, Alberto, La primera Zarzuela moderna, http://www.superopera.com/zarzuela2.htm (Acceso: 16.04.2009).

EZQUERRO ESTEBAN, Antonio, "José de Nebra entre España y la Nueva España: Fuentes documentales de música -Dimensión internacional- para su estudio.”, Lope de Barrientos. Seminario de Cultura, 3, 2010: pp. 59-104.

FLORES ARAOZ, José; et al., Santa Rosa de Lima y su tiempo, Lima, col. “Arte y Tesoros del Perú”, Banco de Crédito de Perú, 1995.

GARBAYO MONTABES, Francisco Javier, Catálogo del Archivo de Música de la Catedral de Ourense, Santiago de Compostela, Instituto Galego das Artes Escénicas e Musicais, Xunta de Galicia, 2004.

GARCÍA FRAILE, Dámaso, Catálogo del archivo de música de la catedral de Salamanca. Cuenca, Instituto de Música Religiosa, 1981.

GUILLÉN BERMEJO, María Cristina, y RUIZ de ELVIRA SERRA, Isabel (coords.), Catálogo de Villancicos y Oratorios en la Biblioteca Nacional. Siglos XVIII-XIX. Madrid, Dirección General del Libro y Bibliotecas-Ministerio de Cultura, 1990.

GUTIÉRREZ ÁLVAREZ, José Antonio, Sonidos de un espacio perdido: la música en las otras iglesias de Madrid en la primera mitad del siglo XVIII, Trabajo inédito realizado para la obtención del D.E.A., Universidad Complutense de Madrid, 2005.

gramas incluyeron obras de Gregorio Remacha y de otros músicos presentes en los archivos musicales del virreinato de la Nueva España. Las obras de Remacha que se pudieron ejecutar en dichas ocasiones fueron: Venid al combite, Luz Gloriosa, y A esta espiga tierna, procedentes del archivo musical del Colegio de Santa Rosa; además de Sacra empresa celestial y Al eco sonoro, que fueron editadas a partir de los manuscritos del archivo de música de la catedral de Salamanca. Todas las obras fueron editadas por quien firma el presente artículo, e interpretadas por maestros y alumnos del Conservatorio de las Rosas, junto con el coro de Niños Cantores de Morelia (bajo la dirección de Elizabeth Espejel), la Coral de las Rosas (bajo la dirección de Ernesto García), así como el ensemble Tiranni Splendori (cuyo director es Alejandro Cardozo). Todos los conciertos fueron coordinados por el autor de estas líneas, y unificados bajo el nombre de Capilla Virreinal de Santa Rosa. 
HOWELL, Almonte, "López, Félix Máximo”, The New Grove Dictionary of Music and Musicians, vol. 15, Stanley SADIE (ed.) Londres, Macmillian, 2001: 174-175.

LÓPEZ CALO, José, Catálogo Musical del Archivo de la Santa Iglesia Catedral de Santiago, Cuenca, Instituto de Música Religiosa de la Excma. Diputación Provincial de Cuenca, Ediciones del Instituto de Música Religiosa, 1972.

LÓPEZ CALO, José, La Música en la Catedral de Palencia, vol. 2, Palencia, Institución Tello de Meneses, 1980.

LÓPEZ CALO, José, La Música en la Catedral de Segovia, vol. II, "Catálogo del Archivo de Música", Segovia, Diputación Provincial de Segovia, 1989.

LÓPEZ CALO, José, La música en la Catedral de Valladolid, vol. III, "Catálogo del Archivo de Música, III”, Actas capitulares, Valladolid, Ayuntamiento de Valladolid, Caja España, 2007.

LÓPEZ CALO, José, La música en la Catedral de Valladolid, vol. VII, "Documentario Musical, I”, Actas capitulares. Valladolid, Ayuntamiento de Valladolid, Caja España, 2007.

MARTÍN MORENO, Antonio, Historia de la Música Española, 4. Siglo XVIII, Madrid, Alianza, 1985.

MARTÍN VÁZQUEZ, Alberto, "Luis de Sandoval y Mallas: autor de villancicos”, en Anuario Musical, 62 (2007): 75-96.

MITJANA, Rafael, "Histoire de la musique en Espagne", Encyclopédie de la Musique et Dictionnaire du Conservatoire. (Albert LAVIGNAC; y Lionel de la LAURENCIE; eds.), vol. IV, París, Delagrave, 1920: 2144.

MURILLO DELGADO, Rubén, El centro histórico de Morelia, Morelia, Fimax publicistas, 1990.

PAREYÓN, Gabriel, "Remacha, Gregorio”, Diccionario de la Música en México, Guadalajara (México), Secretaría de Cultura de Jalisco, 1995: 472.

PAREYÓN, Gabriel, "Remacha, Gregorio”, Diccionario Enciclopédico de Música en México, tomo II, Guadalajara (México), Universidad Panamericana, 2007: 876.

PEDRELL, Felipe, Catàlech de la Biblioteca Musical de la Diputació de Barcelona, vol. I, Barcelona, Palau de la Diputació, 1908.

PENA, Joaquín y ANGLÉS, Higinio, "Remacha, Gregorio Bartolomé”, Diccionario de la Música Labor, tomo II, Barcelona, Labor, 1954: 1856.

RECASENS BARBERÁ, Albert, "Rodríguez de Hita, Antonio", The New Grove Dictionary of Music and Musicians, vol. 21, Stanley SADIE (ed.), Londres, Macmillian, 2001a: 503-504.

RECASENS BARBERÁ, Albert, Las zarzuelas de Antonio Rodríguez de Hita (1722-1787). Contribución al estudio de la zarzuela madrileña hacia 1760-1770, Tesis doctoral, Université Catholique de Louvain, 2001b.

RECASENS, Albert, "Rodríguez de Hita", Músicos de la Magistral, http://www.catedraldealcala.org (Acceso: 11.10.2009).

RUBIO ÁLVAREZ, Samuel, Catálogo del Archivo Musical de la Catedral de León, León, Caja España de Inversiones, Archivo Histórico Diocesano, "Colección y estudios de historia leonesa, 108", 2005 . 
SALDONI, Baltasar, Diccionario biográfico-bibliográfico de efemérides de músicos españoles, tomo IV, Madrid, Antonio Pérez Dubrull, 1868-1881: 273.

SORIANO-FUERTES y PIQUERAS, Mariano, Historia de la música española desde la llegada de los fenicios hasta el año de 1850, 4 vols. Madrid, Antonio Martín y Salazar-Bernabé Carrafa; Barcelona, Narciso Ramírez; 1855-1859. Edición facsímil en 2 vols: (Carreras López, Juan José; ed.) Madrid, ICCMU, col. "Retornos", 2007, tomo IV: 99 -116.

TORRENTE, Álvaro, "Yanguas, Antonio", The New Grove Dictionary of Music and Musicians, vol. 27, Stanley SADIE (ed.), Londres, Macmillian, 2001: 639-640.

Recibido: 06/12/2010

Aceptado: 14/05/2012 